\title{
Fatal Epistaxis Caused by Rupture of an Intratumoral Aneurysm Enclosed by a Large Prolactinoma
}

\author{
-Case Report-
}

\author{
Junichi IMAmUra, Tatuya OKUZONO*, and Yoshiko OKUzONO* \\ Departments of Neurosurgery and *Otolaryngology, Shimonoseki National Hospital, \\ Shimonoseki, Yamaguchi
}

\begin{abstract}
A 72-year-old female presented with episodes of epistaxis. Neuroimaging demonstrated a large prolactinoma totally enclosing a large intracavernous aneurysm of the internal carotid artery. Adjacent bony structures were eroded and destroyed by tumor invasion and extension. Rupture of the intratumoral aneurysm caused fatal epistaxis rather than subarachnoid hemorrhage before surgery. Intratumoral aneurysm is rare and epistaxis caused by rupture of it is extremely rare. Lack of bony protection apparently have contributed to the aneurysmal growth and rupture.
\end{abstract}

Key words: epistaxis, intracavernous aneurysm, intratumoral aneurysm, pituitary tumor, prolactinoma

\section{Introduction}

Epistaxis caused by rupture of intracranial aneurysm usually originates from aneurysms located in the cavernous portion of the internal carotid artery (ICA), and in most cases, was precipitated by head injury. ${ }^{2,4,6,11,12,14)}$ The second most common cause was developmental aneurysm. ${ }^{15)}$ Mycotic aneurysms secondary to the cavernous sinus infection have also caused epistaxis. ${ }^{91}$ Epistaxis from intratumoral aneurysm in the pituitary tumor is very rare. Association of intracranial aneurysm and pituitary tumor is also well known, but an aneurysm totally enclosed by the pituitary tumor is not common. We describe a very unusual case that rupture of an intratumoral aneurysm in the pituitary tumor causing epistaxis which resulted in death.

\section{Case Report}

A 72-year-old female was transferred by ambulance to the Department of Otolaryngology because of sudden epistaxis with headache and nausea on May 18, 1996. Hemostasis was completed with Bellock's tamponade. She was referred to the Department of Neurosurgery. Three months before, she had had two

Received March 19, 1998;

Accepted July 15, 1998 episodes of epistaxis which had subsided without special treatment.

Neurological examination found she was conscious without nuchal rigidity. Her pupils were 3 $\mathrm{mm}$ in diameter on both sides. Only light was distinguishable in her right eye. She had not previously realized the presence of decreased visual acuity of the right eye. No visual defect of the left eye was observed. Eye movement was normal, with no nystagmus. No motor or sensory disturbance was found. Her blood pressure was $200 / 110 \mathrm{mmHg}$. She had no history of head injury, cerebrovascular disease, diplopia, facial pain, aspirin intake, or anticoagulant use.

Computed tomography (CT) showed a giant mass in the sella turcica extending into the sphenoid and ethmoid sinuses, laterally into the cavernous sinus, and slightly into the suprasellar cistern. Another large round mass of higher density was totally enclosed by this giant mass (Fig. 1). Three-dimensional CT angiography revealed a large aneurysm located in the sella turcica, and destruction of the sphenoid sinus bone (Fig. 2). Cerebral angiography showed a large cavernous aneurysm of the right ICA (Fig. 3). There were no feeding arteries or tumor stain. The balloon occlusion perfomed during cerebral angiography caused left hemiparesis. Her serum prolactin level was extremely high at $6800 \mathrm{ng} / \mathrm{ml}$ 


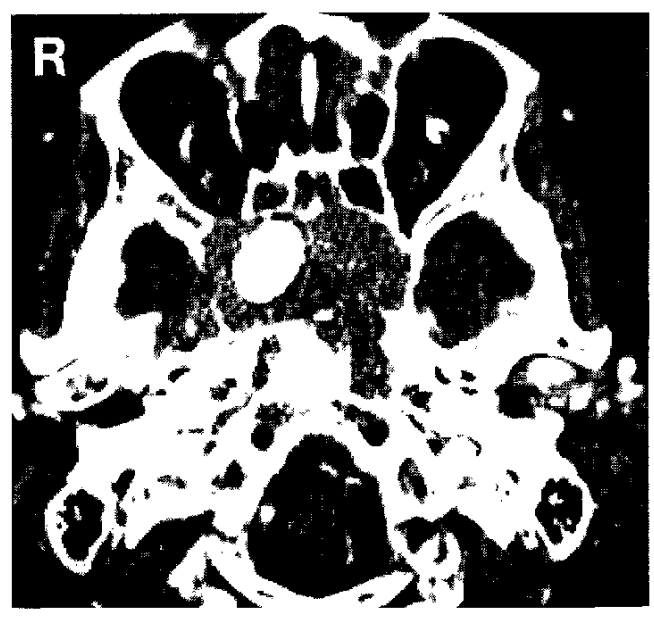

Fig. 1 Computed tomography scan of the head with contrast enhancement showing a high density round mass (aneurysm) totally enclosed by a slightly enhanced irregular shaped mass (tumor) invading into the sphenoid and ethmoid sinuses.

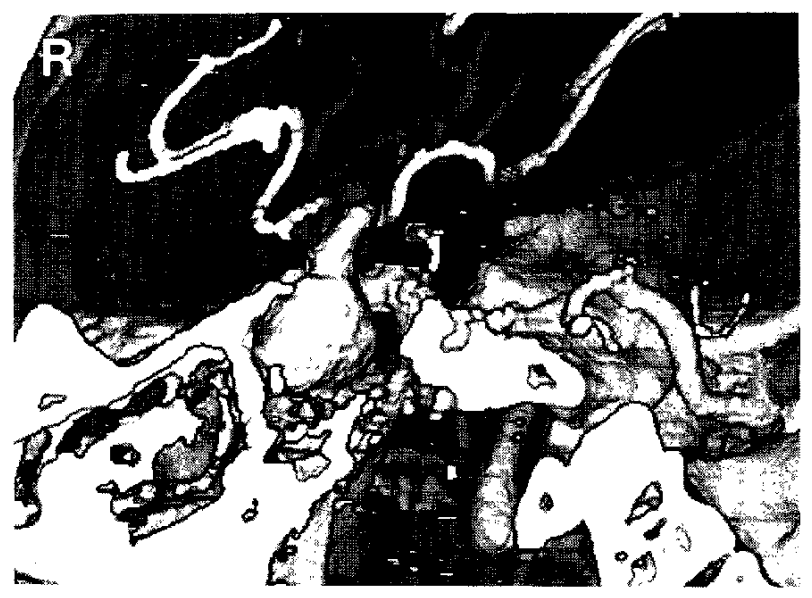

Fig. 2 Three-dimensional computed tomography scan demonstrating a large intracavernous aneurysm of the right internal carotid artery, and destruction of the inferior bony structure.

(normal 1.4-14.6). The diagnosis of the turnor was prolactinoma.

Trapping of the ICA-cavernous aneurysm with extracranial-intracranial bypass was scheduled. However, sudden massive arterial nasal bleeding due to aneurysmal rupture occurred while she was waiting for surgery. Hemostasis of the massive epistaxis filling in the nostril and the oral cavity was difficult to achieve despite continuous compression of the right carotid artery. Consequently, she lost

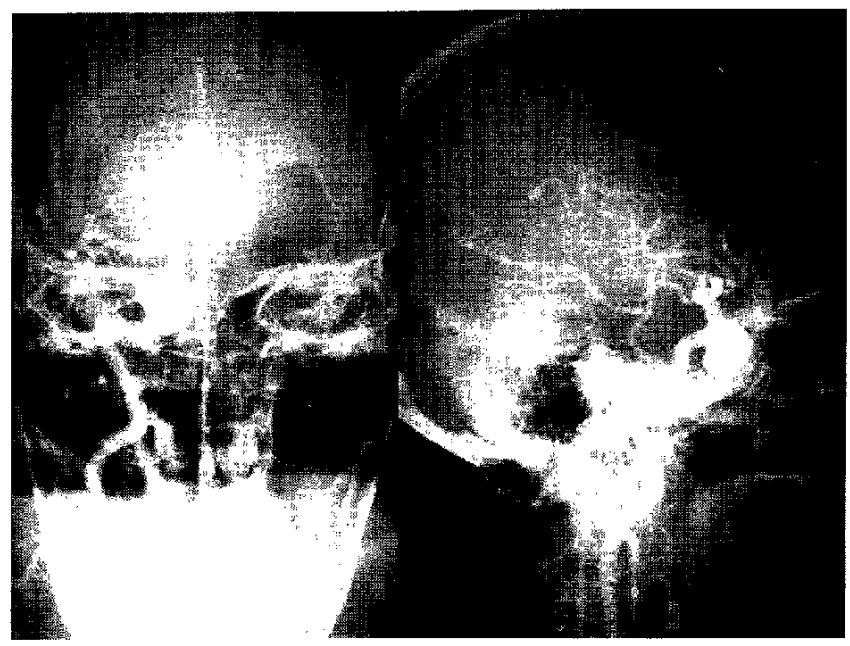

Fig. 3 Right common carotid angiograms showing a large intracavernous aneurysm of the internal carotid artery.

over $1000 \mathrm{ml}$ blood and died in spite of temporary resuscitation on June 6,1996 . Autopsy was refused.

\section{Discussion}

Our patient had no history of head injury, and the ICA-cavernous aneurysm and large prolactinoma was incidentally diagnosed after she complained of headache. This aneurysm seemed to be developmental and the several episodes of minor bleeding before admission were probably from the aneurysm rather than the pituitary tumor. Rupture of the intracranial aneurysm possibly caused epistaxis.

The incidence of intracranial aneurysm associated with pituitary tumor is higher than that in the general population or associated with other brain tumors. ${ }^{1,13)}$ However, such occurrence is only a chance factor and the risk is no greater than that among the general population. ${ }^{10)}$

Most aneurysms associated with pituitary tumor were from adjacent arteries such as the ICA or anterior communicating artery ${ }^{3)}$ and were located close to or touching the pituitary tumor. Aneurysm totally enclosed by the tumor tissue as in our case is very rare. ${ }^{53}$

Several hypotheses ${ }^{\theta)}$ to explain the high frequency of aneurysm associated with pituitary tumor have been proposed, including direct invasion of brain tumor into the cerebral artery, mechanical compression or stretching of the cerebral artery by the brain tumor, rheological stress induced by increased blood supply to the brain tumor, and endocrinological effects on membranous collagen such as growth 
hormone-secreting tumor. ${ }^{14]}$ However, the exact mechanism has not yet been identified.

The ICA-cavernous aneurysm surrounded by hard tissue such as the dura and the bony structures, so is usually unlikely to rupture. In our case, the bony structures were widely eroded and destroyed by the tumor extending and invading inferiorly and anteriorly into the sphenoid and ethmoid sinuses. Therefore, the wall beneath the aneurysm had become less resistant. The aneurysm had apparently grown in the least resistant direction and had subsequently become large enough to rupture. The tumor might have invaded the aneurysmal wall and caused weakening, so the rupture site was probably the most weakened aneurysmal wall. The resistance to intraaneurysmal pressure was also decreased by lack of bony protection. Therefore, she did not suffer subarachnoid hemorrhage although the aneurysm had bled only into the nostril.

Various surgical strategies for the treatment of ICA-cavernous aneurysm are available, including ligation, balloon occlusion, ${ }^{6,8,11)}$ coil embolization ${ }^{15)}$ of the ICA, trapping of the ICA-cavernous portion, ${ }^{7,14)}$ and neck clipping of the aneurysm. Simultaneous neck clipping and tumor resection is often successfully performed in cases of ICA aneurysm associated with pituitary tumor, ${ }^{3]}$ but not in cases of intratumoral aneurysm. ICA trapping with extracranial-intracranial bypass was scheduled for our patient because of the neurological deficits provided by the balloon occlusion test. Unfortunately she died before surgery. Emergent surgery is recommended in such cases.

\section{References}

1) Crandon IW, Teasdale E, Galbraith SL, Hadley DM: Carotid traumatic aneurysm treated by detachable balloon. B $\mathrm{J}$ Neurosurg 2: 507-511, 1988

2) Destian S, Tung H, Gray R, Hinton DR, Day J, Fukushima T: Giant infectious intracavernous carotid artery aneurysm presenting as intractable epistaxis. Surg Neurol 41: 472-476, 1994

3) Fujiwara S, Fujii K, Nishio S, Fukui M: Diagnosis and treatment of pituitary adenoma with adjacent carotid artery aneurysm. J Neurosurg Sci 35: 41-46, 1991

4) Handa J, Handa $\mathrm{H}$ : Severe epistaxis caused by traumatic aneurysm of cavernous carotid artery. Surg
Neurol 5: 241-243, 1976

5) Kagawa R, Shima $T$, Matumura S, Okada $Y$, Nishida M, Yamada T, Okita S: [A case of a large prolactinoma complicated with the intratumorous large aneurysm - Findings by magnetic resonance imaging]. Hiroshima Igaku 43: 382-385, 1991 (Jpn)

6) Larson JJ, Tew JM Jr, Tomsick TA, van Loveren HR: Treatment of aneurysms of the internal carotid artery by intravascular balloon occlusion: Long-term follow-up of 58 patients. Neurosurgery 36: 23-30, 1995

7) Liu M, Shih C, Wang Y, Tsai S: Traumatic intracavernous carotid aneurysm with massive epistaxis. Neurosurgery 17: 569-573, 1985

8) McGrail KM, Heros RC, Debrun G, Beyerl BD: Aneurysm of the ICA petrous segment treated by balloon entrapment after EC-IC bypass. J Neurosurg 65: 249-252, 1986

9) Moore D, Budde RB, Hunter CR, Mayfield FH: Massive epistaxis from aneurysm of the carotid artery. Surg Neurol 11: 115-117, 1979

10) Pant B, Arita K, Kurisu K, Tominaga A, Eguchi $K$, Uozumi T: Incidence of intracranial aneurysm associated with pituitary adenoma. Neurosurg Rev 20: 1317,1997

11) Reiber ME, Burkey BB: Intracavernous carotid pseudoaneurysm after blunt trauma: Case report and discussion. Head Neck 16: 253-258, 1994

12) Simpson RK Jr, Harper RL, Bryan RN: Emergency balloon occlusion for massive epistaxis due to traumatic carotid-cavernous aneurysm. I Neurosurg 68: 142-144, 1988

13) Wakai S, Yamakawa K, Manaka S, Takakura K: Spontaneous intracranial hemorrhage caused by brain tumor: its incidence and clinical significance. Neurosurgery 10: 437-444, 1982

14) Wang AN, Winfield JA, Gücer G: Traumatic internal carotid artery aneurysm with rupture into the sphenoid sinus. Surg Neurol 25: 77-81, 1986

15) Yang $X$, Saari $T$, Kansanen $M$, Puranen $M$, Soimakallio S: Epistaxis from nontraumatic intracavernous carotid aneurysm: Endovascular treatment with detachable coils and electrothrombosis. Am J Otolaryngol 16: 255-259, 1995

Address reprint requests to: J. Imamura, M.D., Department of Neurosurgery, Shimonoseki National Hospital, 11-1 Ushiroda-cho, Shimonoseki, Yamaguchi 7518501, Japan. 